\title{
Dehydrated Human Amnion Chorion Membrane as Treatment for Pediatric Burns
}

\author{
Natasha Ahuja, ${ }^{1, *}$ Richard $\mathrm{Jin}^{2}$ Colin Powers, ${ }^{2}$ \\ Alexandria Billi, ${ }^{2}$ and Kathryn Bass ${ }^{1,2, *}$ \\ ${ }^{1}$ Department of Surgery, University at Buffalo Jacobs School of Medicine and Biomedical Sciences, Buffalo, New York, USA \\ ${ }^{2}$ Department of Pediatric Surgery, John R. Oishei Children's Hospital, Buffalo, New York, USA.
}

Objective: Pediatric burns are a major source of injury and in the absence of adequate care can lead to lifelong functional loss and disfigurement. While split thickness skin autografts are the current standard of care for deep partial and full-thickness burns, this approach is associated with considerable morbidity. For this reason, alternative skin substitutes such as allografts have gained interest. Approach: In the present study, we present a case series of 30 children with various types of burns treated with dehydrated human amnion chorion membrane (dHACM).

Results: We show that treatment with dHACM is associated with an excellent rate of healing comparable to split thickness skin grafts with less rate of hypertrophic scar and contracture.

Innovation: Treatment with $\mathrm{dHACM}$ is particularly attractive as it consists of many tissue regenerative factors, such as growth factors and immune modulators, thus it will reduce the risk of scaring.

Conclusion: While dHACM is associated with an increased upfront cost, treating patients with small to moderate-sized burns with dHACM in their regional centers works to decrease downstream costs such as management of prolonged pain from donor-site morbidity, revisional surgeries from scar and contractures of split thickness grafts, and avoiding the cost of transfer to higher level centers of care. Our findings challenge the current standard of care, suggesting that dHACM provides an alternative to the current use of split thickness skin grafting and is a safe, feasible, and potentially superior substitute for the management of small to moderate total body surface area partial and full-thickness pediatric burns.

Keywords: dehydrated human amnion chorion membrane allografts, pediatric burns, pediatric wound care

\section{INTRODUCTION}

BURN INJURIES ARE a prevalent and devastating cause of unintentional morbidity and mortality in the United States. In 2015, burn injuries resulted in 356,000 visits to the emergency departments. ${ }^{1}$ The pedi- atric population (age 1-15) is particularly vulnerable, accounting for $23.5 \%$ of total burn cases, second only in prevalence to the adult age group (age 20-59), accounting for 55\%., For severe burn wounds, patients are often transferred to dedicated burn Buffalo, NY, 14203, USA

(e-mail: KBass@kaleidahealth.org).

(C) Natasha Ahuja, et al., 2020; Published by Mary Ann Liebert, Inc. This Open Access article is distributed under the terms of the Creative Commons License (http://creativecommons.org/licenses/by/ 4.0), which permits unrestricted use, distribution, and reproduction in any medium, provided the original work is properly cited. 
centers. Referral criteria to burn centers include extensive burns; that is, partial thickness burns $>10 \%$ total body surface area (TBSA) as well as burns to face, hands, feet, and genitalia. American Burn Association (ABA) data from 2008 to 2017 demonstrated that $67 \%$ of burns treated in ABA centers were $<10 \%$ TBSA involving the face, hands, feet, genitalia, perineum, or major joints. ${ }^{3,4}$ This population does not require the significant fluid resuscitation and critical care of specialized burn centers and presents a target opportunity for the use of dehydrated human amnion chorion membrane (dHACM) in children. Keeping families together in their own regional hospitals without the burden of travel to receive care provides a major benefit to families and their social support during treatment and recovery.

The management of severe pediatric thermal burns is varied and dependent on the severity of burn. In the absence of adequate treatment, burns can result in significant scarring, contracture, and loss of function. ${ }^{5}$ The current standard of treatment for deep partial thickness and full-thickness burns is surgical debridement of nonviable tissue followed by split thickness skin grafting (STSG). ${ }^{5,6}$ Although widely used in adults, skin autografts pose additional challenges to the pediatric population. An autograft allows coverage of the burn wound, which will reduce pain, fluid loss, and risk of infection at the primary site; but, at the cost of creating a secondary wound that is reported by patients as a greater source of pain than the primary injury, and creates another site for potential fluid loss, infection, and poor cosmesis. ${ }^{5}$ A variety of allograft products and acellular dermal substitutes are available for the treatment of burns and have demonstrated some efficacy in the treatment of pediatric burn wounds. ${ }^{5,6}$ An ideal pediatric burn wound graft should be infection resistant, cost effective, available widely with a long shelf life, lack antigenicity, be flexible to the depth and contour of the wound, durable without need for replacement, and easy to apply and secure. We chose to focus on dHCAM as an alternative to allograft due to its role in modulating immunologic parameters, allowing burn wound repair and meeting many of the objectives listed above. ${ }^{7}$

\section{CLINICAL PROBLEM ADDRESSED}

Wound healing is a highly dynamic process reliant on well-coordinated phases of repair. While repair is determined by the ability of diverse stem cell populations to repopulate the damaged niche, the efficacy of tissue regeneration is highly driven by the immune process. ${ }^{8-15}$ Decoupling the temporal or qualitative nature of immune responses in the context of wound healing leads to chronic wounds or aberrant regeneration. ${ }^{12,16,17}$ Regardless of the insult, the immunity in most tissues follows a very stereotypic response, leading to efficient repair. However, a number of factors can inhibit this response.

After an injury, damaged tissue and tissueresident macrophages secrete a number of chemokines that facilitate the rapid influx of innate immune cells, including neutrophils and inflammatory monocytes. ${ }^{11,18-23}$ Natural killer cells and $\mathrm{T}$ cells also enter the tissue and act in concert to drive the differentiation of inflammatory monocytes into inflammatory macrophages. ${ }^{14,19,21,24}$ Collectively, these cells constitute the acute inflammatory phase of repair necessary for induction of the immune response, activation of stem cell populations, and clearance of necrotic debris. ${ }^{14,19-21,23,25}$ As the repair proceeds, wound healing enters a regenerative phase marked by migration and proliferation of tissue-resident stem cells and ultimately, tissue remodeling. ${ }^{20,26-29}$ These phases are mirrored by a transition from inflammatory macrophage-mediated repair to restorative macrophage-mediated repair as well as

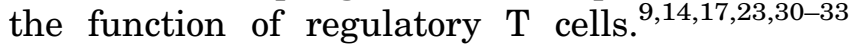
Collectively, both immune subsets play a dual role in quelling overt inflammation and producing growth factors and tissue remodeling factors such as members of the epidermal growth factor and matrix metalloproteinase families. ${ }^{9,20,23,34-36}$ While the factors that directly mediate the transition toward the regenerative phase are not completely understood, various immune modulatory cytokines have been implicated, such as IL-10. ${ }^{37}$

dHACM has been shown to reduce scar tissue formation and enhance wound healing in diabetic foot ulcers, venous leg ulcers, and select burn cases. $^{7,38-40}$ This therapeutic benefit may be imparted by the ability of human amniotic membrane to not only provide a biologic barrier for the wound but also modulate inflammation and growth factors to foster an enriched regenerative tissue environment. The human amniotic membrane is composed of two conjoined membranes, amnion and chorion. The amnion faces the fetus and consists of organized collagen-rich extracellular matrix, viable cells, regulatory proteins, and signaling molecules. ${ }^{41}$ It is comprised of five distinct layers: the epithelium, basement membrane, compact layer, fibroblast layer, and spongy layer. ${ }^{41}$ The chorion is uterus facing, three to four times thicker than the amnion, and comprised of a reticular layer, 
basement membrane, and trophoblast layer. ${ }^{41}$ Importantly, amniotic membrane grafts harbor a number of developmental cytokines that play important roles in tissue formation. ${ }^{42}$ Together, these factors aid in development as the tissue must grow and expand without scar tissue formation to successfully carry the growing fetus. Previously, 226 growth factors, cytokines, and chemokines have been identified in dHACM. ${ }^{43-47}$

Given the ability of dHACM to influence multiple modalities of repair, we sought to determine the clinical efficacy of using dHACM in the treatment of pediatric small and moderate TBSA partial and full-thickness burns at risk of functional deficits.

\section{MATERIALS AND METHODS}

We performed a retrospective chart review between 2017 and 2018, and selected 30 burns that involved the face, hands, feet, genitalia, and major joints occurring in children between 0 and 18 years presenting to our Children's Hospital. Patients with $>20 \%$ TBSA burns were transferred to a Pediatric Burn Center. The patients were divided into three groups, including superficial partial thickness, deep partial thickness, and full-thickness burn injuries. Data collected included patient age, gender, mechanism of burn, \% body surface area, body region, number of weeks to complete healing, and reported pain after dHACM grafting. The literature was reviewed for time to healing of STSG based on depth of burn wound. ${ }^{48-55}$ These results were tabularized, and were compared with rates of healing for dHACM grafts dependent on depth of burn wound.

All burns were treated in the operating room (OR) with a primary sharp debridement of grossly dead and devitalized tissue followed by an ultrasonic debridement of the wound bed until fine bleeding was provoked. Hypochlorous acid was used to wash the surface of the wound before application of the dHCAM graft to each site. The grafts were hydrated by the wound surface and became immediately adherent, then additionally held in place by a porous, emollient noncontact layer sutured around the wound. Surgical lubricant was layered onto the noncontact layer, and then the wound was dressed with nonadherent gauze pad and soft roll. To secure the dressing as childproof for 1 week, an elastic bandage and selfadherent wrap were applied. In the case of hand burns, to immobilize the hand from movement, after applying the soft roll, a fiberglass cast was applied to the mid upper arm over a $90^{\circ}$ bent elbow.

Patients were seen weekly for dressing changes. The outer dressing was removed down to the emollient noncontact layer, and hypochlorous acid was used as a wound cleanser to remove any excessive exudate that had extruded through the porous noncontact layer. Depending on the age, some of these cases were taken to the OR to assist the child with sedation to allow for thorough cleaning and redressing of the burn. At week 2, the emollient noncontact layer was removed and only replaced if there was still burn wound surface that had not re-epithelialized. Time to complete burn wound healing and patient satisfaction was assessed at each weekly visit. Pain scores were assessed weekly using the Wong-Baker FACES score scale, and scars were assessed using the Vancouver Scar Scale (VSS) at the 6-week appointment after completion of the re-epithelialization. Any complications encountered were charted weekly.

\section{RESULTS}

All burns treated in our center, with the exception of two cases (which were $15 \%$ and $17 \%$ TBSA), were treated with maintenance fluid on presentation, did not require significant fluid resuscitation, that is, Parkland formula, and were managed as outpatients. Pain was exceptionally well controlled in all cases without the use of narcotics by using scheduled Acetaminophen and Ibuprofen alternating at 3 -hr intervals, while the child was awake over the first $48 \mathrm{~h}$. Parents and caregivers were instructed to use this routine thereafter as needed. Parents reported good pain control with this approach and at weekly intervals, $0-1$ points was achieved for all patients on the Wong-Baker FACES scale.

Dressings remained intact for the majority of children. For the few who were able to deconstruct our elaborate multilayer wrap, inspection in the emergency department or in clinic revealed that

Table 1. Superficial partial thickness burns

\begin{tabular}{|c|c|c|c|c|c|c|}
\hline Age/Gender & Mechanism of Burn & Body Region & $\%$ TBSA & $\begin{array}{l}\text { No. of Weeks to } \\
\text { complete healing }\end{array}$ & VSS & Complications \\
\hline 14-Month male & Contact heat burn & Left palmar surface of second to fifth digits & 1 & 3.5 & 1 & Hypertrophic scarring \\
\hline 2-Year female & Spilled hot coffee & Chest (including b/l nipples), right arm & 6 & 3 & 0 & \\
\hline 18-Month female & Spilled hot oil & $\begin{array}{l}\text { Right buttock, right posterior thigh, posterior } \\
\text { LLE, left medial ankle }\end{array}$ & 6 & 3 & 1 & \\
\hline
\end{tabular}

LLE, left lower extremity; TBSA, total body surface area; VSS, Vancouver Scar Scale. 
Table 2. Deep partial thickness burns

\begin{tabular}{|c|c|c|c|c|c|c|}
\hline Age/Gender & Mechanism of Burn & Body Region & $\% T B S A$ & $\begin{array}{l}\text { No. of Weeks } \\
\text { to Complete } \\
\text { Healing }\end{array}$ & VSS & Complications \\
\hline 17-Month male & Unknown mechanism & Left fingers, circumferential & $<1$ & 3 & 1 & Hypertrophic scarring \\
\hline 11-Month male & Dunked hand into hot water & Left palm and digits & 1 & 2.5 & 0 & \\
\hline 17-Year male & Fire burn from gasoline & Right hand & 1 & 2.5 & 0 & \\
\hline 16-Month male & Placed hand on cast iron stove & Left hand & 1 & 4 & 0 & \\
\hline 13-Month male & Touched open oven door & Bilateral hands & 2 & 4 & 0 & $\begin{array}{l}\text { Fungal infection noted } \\
\text { after third dressing change }\end{array}$ \\
\hline 17-Month male & Ramen noodle spill & RUE & $3-4$ & 4 & 1 & \\
\hline 8-Year male & Placed into hot water tub & $\begin{array}{l}\text { Bilateral feet (circumferential } \\
\text { around digits) }\end{array}$ & 3 & 5 & 1 & \\
\hline 3-Year female & $\begin{array}{l}\text { Fall into fire embers } \\
\text { while camping }\end{array}$ & Lower back and left arm & 3 & 4 & 1 & \\
\hline 7-Month male & Crawling on hot furnace & Bilateral hands, abdomen & $\begin{array}{c}4 \text { (1\% each hand, } \\
2 \% \text { abdomen) }\end{array}$ & 3.5 & 1 & \\
\hline 12-Month female & Curling iron & LLE & 4 & 3 & 0 & \\
\hline 16-Year female & Spilled hot tea & Labia majora, bilateral inner thighs & 5 & 4 & 0 & \\
\hline 10-Month male & Pulled hot tea onto self & RUE & 5 & 2.5 & 0 & \\
\hline 5-Month female & $\begin{array}{l}\text { Scald burns from hot } \\
\text { water in tub }\end{array}$ & $\begin{array}{l}\text { Bilateral thighs, groins, perineum, } \\
\text { lower abdomen }\end{array}$ & 5 & 3 & 0 & \\
\hline 17-Month male & Fall onto hot coals & Bilateral hands and knees & 5 & 2.5 & 0 & \\
\hline 2-Year male & Spilled tea on self & Bilateral LE & $\begin{array}{l}6(5 \% \text { on right leg, } \\
1 \% \text { on left) }\end{array}$ & 2 & 1 & Hypertrophic scarring \\
\hline 12-Year female & Grease fire & Face, right arm, left leg & 8 & 4 & 2 & $\begin{array}{l}\text { Scratches due to itching, } \\
\text { dog scratched left leg }\end{array}$ \\
\hline 9-Month male & Unknown mechanism & Face, left neck, auricular area & 10 & 4 & 0 & \\
\hline 4-Week male & Accidental hot water & $\begin{array}{l}\text { LLE, including knee joint, foot, } \\
\text { and perineum }\end{array}$ & 10 & 2.5 & 0 & \\
\hline 17-Month male & Spilled hot tea & Chest, bilateral arms & 10 & 4 & 1 & Hypertrophic scarring \\
\hline 18-Month female & Pulled hot tea onto self & $\begin{array}{l}\text { LUE, chest (including nipple), } \\
\text { abdomen }\end{array}$ & 12 & 3 & 2 & $\begin{array}{l}\text { Admitted POD\#5 for fever and } \\
\text { vomiting, but no signs of infection; } \\
\text { early hypertrophic scarring-resolved } \\
\text { compression dressing }\end{array}$ \\
\hline 15-Month male & Pulled hot water pot & Face, chest, and left arm/axilla & 15 & 1.5 & 1 & $\begin{array}{l}\text { During } \mathrm{OR} \text {, patient developed } \\
\text { hypothermia and } \\
\text { was recovered in PICU for } \\
\text { warming; complained of itching }\end{array}$ \\
\hline 12-Year female & $\begin{array}{l}\text { Crockpot water fell } \\
\text { onto patient }\end{array}$ & Right thigh, RUE, abdomen & 17 & 2 & 0 & \\
\hline
\end{tabular}

LE, lower extremity; LUE, left upper extremity; OR, operating room; RUE, right upper extremity.

the grafts were held in place with emollient layer intact. Unlike skin grafting where the percentage take is variable across different wound types and fails to engraft on bone or tendon, $\mathrm{dHACM}$ is capable of stimulating granulation tissue and sub- sequent epithelialization over a larger variety of wound types, including bone and tendon.

While gathering data, we looked at the average time to the OR for debridement and graft placement after initial injury. Not all wounds presented

Table 3. Full-thickness burns

\begin{tabular}{|c|c|c|c|c|c|c|}
\hline Age/Gender & Mechanism of Burn & Body Region & $\%$ TBSA & $\begin{array}{l}\text { No. of Weeks } \\
\text { to Complete Healing }\end{array}$ & VSS & Complications \\
\hline 17-Month male & Fall onto wood burning stove & Bilateral finger pads and palms & $1-2$ & 5 & 1 & \\
\hline 3-Year female & Treadmill burn & $\begin{array}{l}\text { Bilateral hands with exposed } \\
\text { tendon at PIP joint }\end{array}$ & 2 & 2 & 5 & Scar contracture \\
\hline 10-Year male & Gas can explosion & Left ear and left LE & 3 & 9 & 0 & $\begin{array}{l}\text { Friction blisters, poor wound care- } \\
\text { fungal infections }\end{array}$ \\
\hline 13-Month female & Pulled hot tea & RUE & 3 & 4 & 1 & $\begin{array}{l}\text { Minor hypertrophic scarring, poor } \\
\text { follow-up as patient was out of } \\
\text { town for a month }\end{array}$ \\
\hline 3-Year female & Spilled hot soup & $\begin{array}{l}\text { Left upper thigh and } \\
\text { suprapubic region }\end{array}$ & 8 & 5 & 0 & $\begin{array}{l}\text { Emergency department visit: concern } \\
\text { for infection, none observed }\end{array}$ \\
\hline
\end{tabular}

PIP, proximal interphalangeal. 
Table 4. Summary statistics

\begin{tabular}{|c|c|c|c|c|c|}
\hline $\begin{array}{l}\text { Burn Depth } \\
\text { Thickness }\end{array}$ & Sample Size & $\begin{array}{c}\text { Average Time to OR } \\
\text { After Initial Injury (Days } \pm S D)\end{array}$ & $\begin{array}{c}\text { Average Time to Complete } \\
\text { Healing (Days } \pm S D)\end{array}$ & $\begin{array}{l}\text { Average Surface } \\
\text { Area }\left(\mathrm{cm}^{2} \pm S D\right)\end{array}$ & Average VSS \\
\hline Superficial partial & 3 & $4.7 \pm 3.5$ & $22 \pm 2.6$ & $31.8 \pm 18.9$ & $0.67 \pm 0.58$ \\
\hline Deep partial & 22 & $2.5^{\mathrm{a}} \pm 2.6$ & $23 \pm 6.2$ & $167.8 \pm 220.5^{b}$ & $0.59 \pm 0.67$ \\
\hline Full & 5 & $10^{C} \pm 8.7$ & $49^{d} \pm 19.8$ & $75.9 \pm 58$ & $1.4 \pm 2.07$ \\
\hline
\end{tabular}

immediately after injury creating a wide variation in time to surgical debridement. In superficial partial thickness burns $(n=3)$, time to OR averaged 4.7 days $( \pm 3.5)$. Deep partial thickness burns $(n=22)$ averaged 2.5 days $( \pm 2.6)$, while fullthickness burns $(n=5)$ took an average of 10 days ( \pm 8.7$)$. The results of the full-thickness burns were skewed by three different cases where the patients presented 2-3 weeks after initial injury in the office with wounds that were stalled. Typically, patients who presented immediately after the initial injury to the emergency department with a full-thickness burn were taken to the OR the next day. Tables 1-3 provide the specifics of the patients within this study, demonstrating mechanism, location, and time to heal.

The average surface area and the average number of days to complete healing were calculated. For superficial partial thickness burns, the average surface area affected was $31.8 \mathrm{~cm}^{2}( \pm 18.9)$ with an average time to complete healing of 22 days $( \pm 2.6)$. The average surface area affected for deep partial thickness burns was $167.8 \mathrm{~cm}^{2}( \pm 220.5)$ with an average time to complete healing of 23 days $( \pm 6.2)$. Finally, the average surface area affected for fullthickness burns was $75.9 \mathrm{~cm}^{2}( \pm 58)$ with an average time to complete healing of 49 days $( \pm 14.9)$. The time to healing in the full-thickness burns was skewed as there was one patient who took 63 days to heal as a result of missed clinic appointments and poor compliance to wound care and immobilization. Table 4 summarizes the results we found in this study. Figures 1-3 demonstrate findings for the various burns at initial injury, week 1 after dHACM grafts, and complete healing for each burn depth group. Consent was obtained from the children's parents for their photographs to be used for this article.

VSS was applied to burn wounds at the completion of re-epithelialization and at a 6-week follow-up scar evaluation. Most patients had scores of 0-2 at 6 weeks with normal vascularity and pliability upon re-epithelialization. There were also a few cases with hypopigmentation and a few with hypertrophic scars (HTS) that were $<2 \mathrm{~mm}$ in height. However, there was one case with a score of 5 as the patient developed minor contractures after 6 weeks.

While STSG is the current standard, it is associated with known complications, including the development of contractures and subsequent need for revisional surgery. ${ }^{48}$ The dHACM results describing time to healing and complications with HTS/contractures were compared with results from previously described STSG studies. ${ }^{49-56}$ The time to healing for dHACM on average was less than STSG, as it took 15-21 days to heal the various depths of burns while STSG took on average $>21$ days, as demonstrated in Table 5. The rates of HTS and contractures of dHACM grafts were compared with eight representative studies describing STSG. Deep and full-thickness burn injuries face the greatest risk of HTS and contractures. For these injuries, dHACM resulted in $18.5 \%$ rate of HTS and contractures, in comparison with STSG studies, which resulted in $57 \%$ and $64.1 \%$, see Cubison $^{55}$ and Rotatori, ${ }^{49}$ respectively (Table 6).

\section{DISCUSSION}

Pediatric burns are a cause of long-term morbidity and can result in a lifetime of functional and esthetic disfigurement. The current standard of care for small to moderate TBSA deep partial and full-thickness burns calls for surgical debridement and rapid autografting, often at a dedicated burn center. ${ }^{5,6}$ However, this approach is subject to a number of challenges that adversely affect both the efficacy and cost of care. We present a case series of 30 children who demonstrate the utility of dHACM as an efficacious substitute for autografts in the management of complex pediatric burn wounds. The use of allografts as skin substitutes such as dHACM circumvents the need to generate a donor site, thereby eliminating associated donor-site morbidity. In addition to dHACM, a number of allograft strategies are underdevelopment, including biologic grafts (porcine and cadaveric skin), synthetic material (hydrocolloids and hydrogels), and 
a

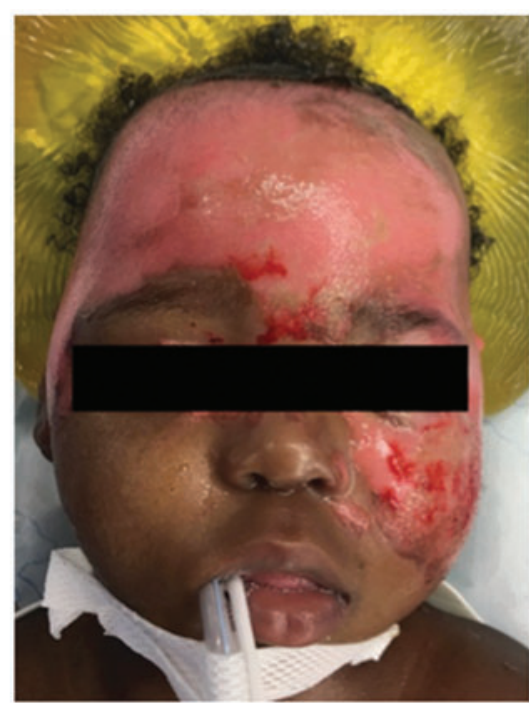

C

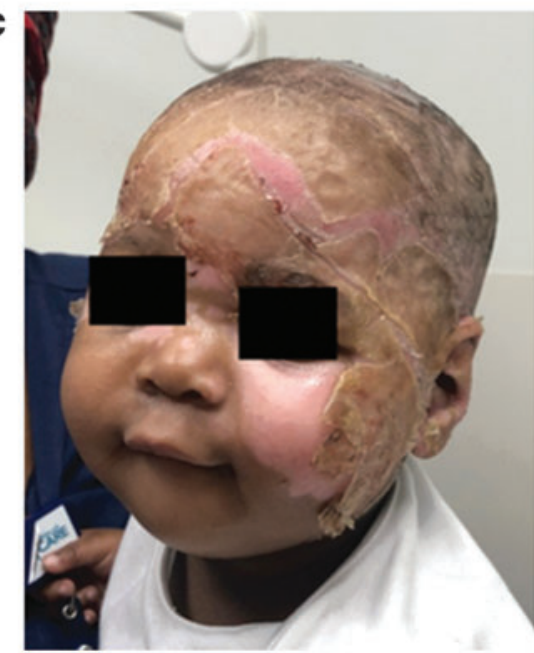

b

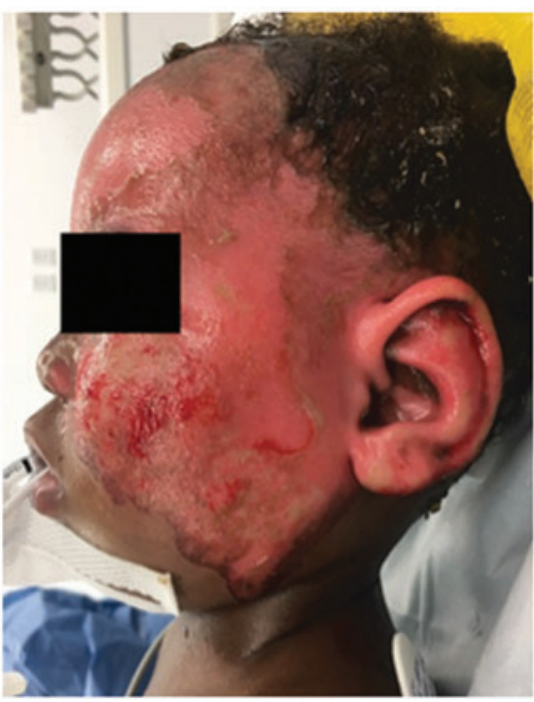

d

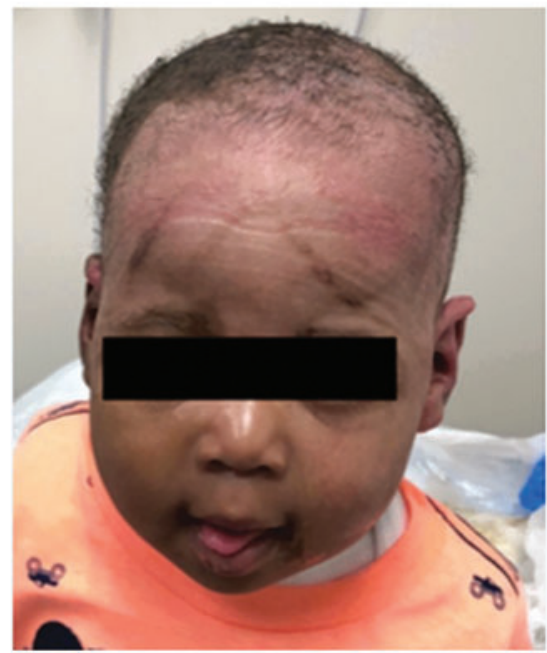

Figure 1. Superficial partial thickness facial burn with rapid return to natural skin tone after $\mathrm{dHACM}$ graft. (a, b) Initial debridement, (c) postop day 7, and (d) complete healing. dHACM, dehydrated human amnion chorion membrane.
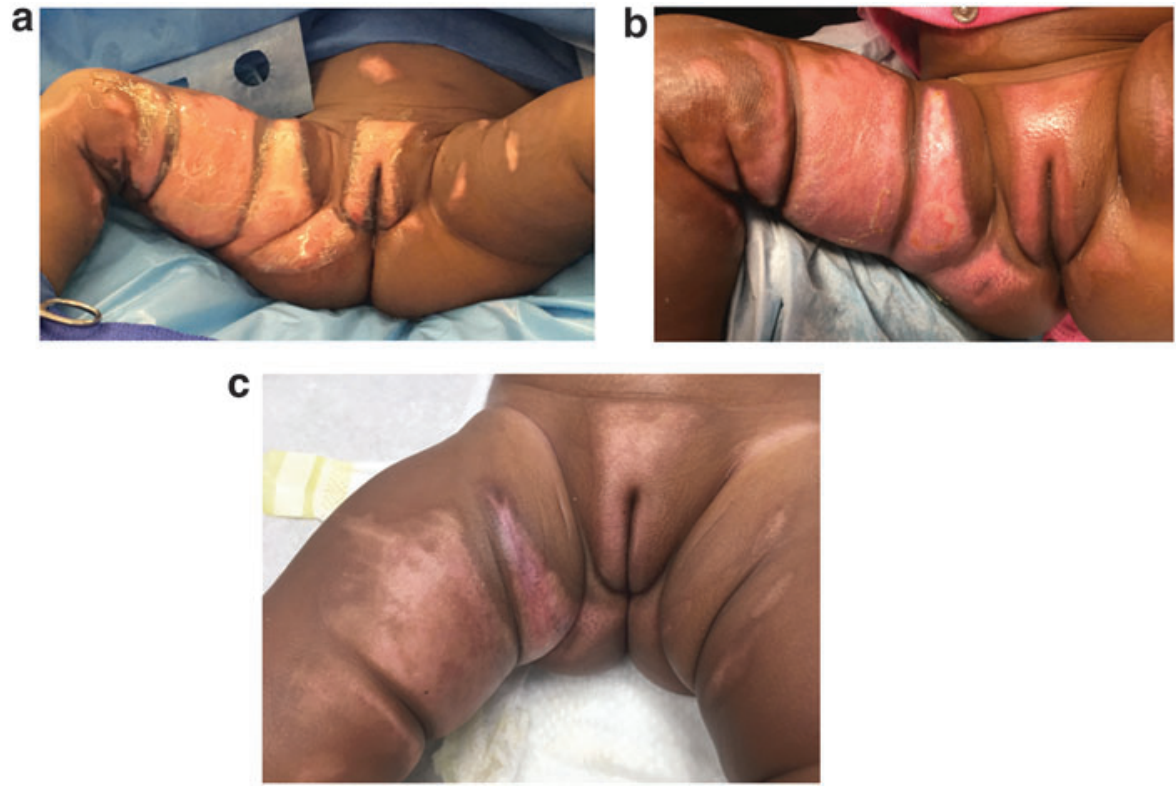

Figure 2. Deep partial thickness genitalia burn. (a) Initial debridement after grafting, (b) postop day 7, (c) complete healing at week 3 with normal skin quality no scarring. 

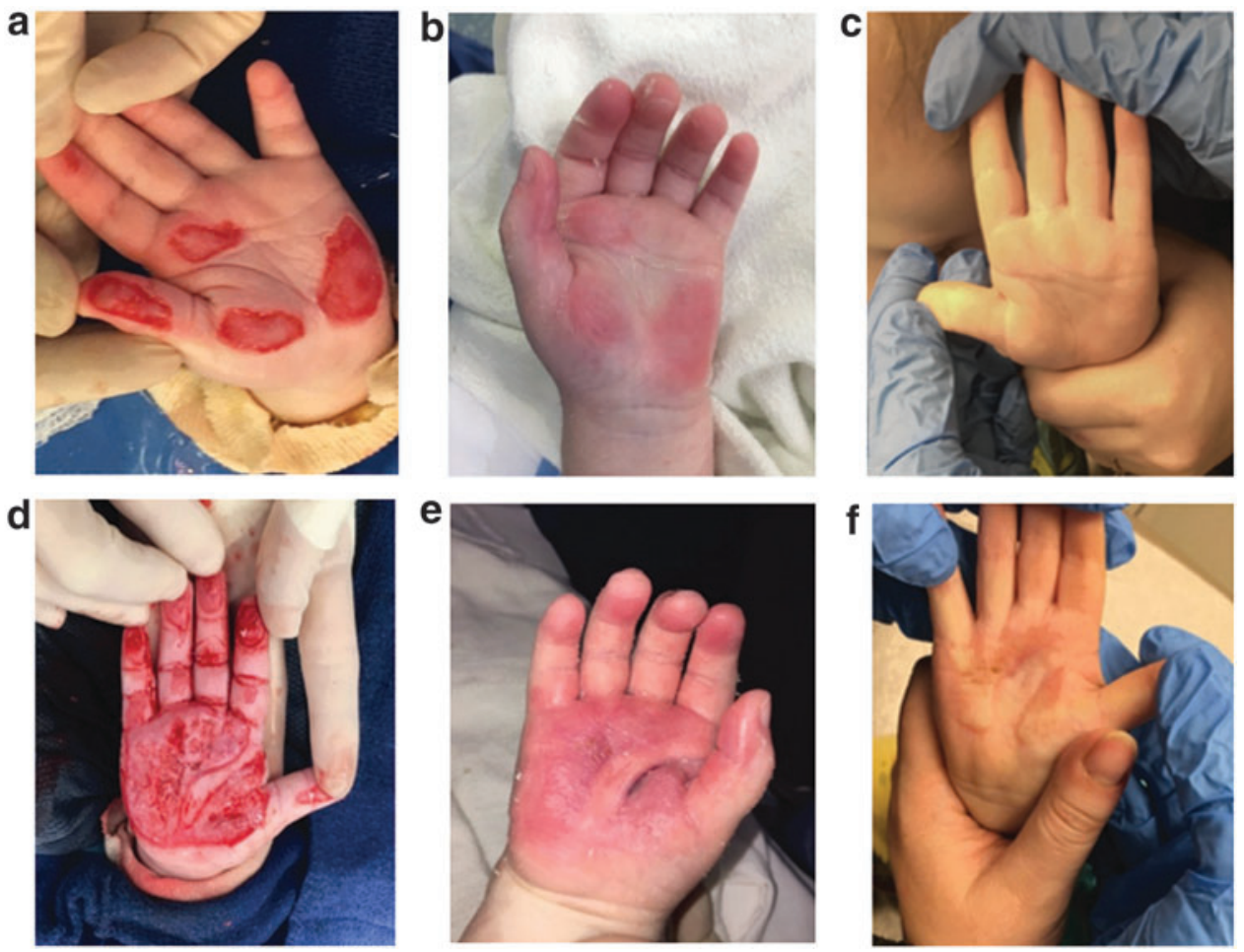

Figure 3. Full-thickness hand burns to fingers bilaterally (a, d) initial debridement, (b, e) complete healing postop day 38, (c, f) postop day 115 with no contractures and minimal scarring.

biosynthetics (Integra, Apligraf, and Dermagraft). To date, few randomized-controlled trials have compared the efficacy of these allografts in pediatric burns. Cadaveric skin has posed a number of obstacles not limited to potential disease transmission and psychologic rejection of donor skin due to potential differences in skin tone. In a longitudinal assessment of Integra in primary burn management, Integra resulted in better cosmesis compared with autograft-allograft treatment. ${ }^{57}$ Many of these products involve only a dermal layer; patients must still be autografted after treatment due to the lack of an epidermal layer. Apligrapf contains an epidermal layer, but its major adverse effect in clinical trials was a twofold increased wound infection rate. ${ }^{58}$ In addition, Apligraf has a short shelf life of only 15 days. ${ }^{58}$

We specifically chose dHCAM as a burn graft for patients with injuries to areas vulnerable to functional deficit from scarring such as hands, feet, face, genitalia, and joints. Although there is no limit to the body surface area that can be treated with dHACM, its cost prohibited us from using it except in these vulnerable areas. We anticipate that we could have achieved excellent results using dHCAM in all areas; however, we chose less costly dressings if we could achieve burn surface area coverage that would not compromise function due

Table 5. Time to healing of dehydrated human amnion chorion membrane versus split thickness skin grafting

\begin{tabular}{|c|c|c|c|c|c|c|c|c|}
\hline \multirow{2}{*}{\multicolumn{2}{|c|}{ Time to Healing }} & \multicolumn{4}{|c|}{ dHACM } & \multicolumn{3}{|c|}{ STSG } \\
\hline & & $\begin{array}{c}\text { Superficial Partial } \\
\text { Thickness }\end{array}$ & $\begin{array}{l}\text { Deep Partial } \\
\text { Thickness }\end{array}$ & $\begin{array}{c}\text { Full } \\
\text { Thickness }\end{array}$ & Total & $\begin{array}{c}\text { Kishikova et al. }{ }^{56} \\
\text { Superficial Partial, Deep Partial, } \\
\text { Full Thickness }\end{array}$ & $\begin{array}{l}\text { Cubison et al. }{ }^{55} \\
\text { Deep Partial/ } \\
\text { Full thickness }\end{array}$ & $\begin{array}{c}\text { Lonie et al. } \\
\text { N/A }\end{array}$ \\
\hline $1-14$ days & $n(\%)$ & $0(0)$ & $3(13.6)$ & $1(20)$ & $4(13.3)$ & $1(7.1)$ & $16(18.6)$ & $0(0)$ \\
\hline 15-21 days & $n(\%)$ & 2 (66.7) & $9(40.9)$ & $0(0)$ & 11 (36.7) & $1(7.1)$ & 16 (18.6) & 1 (4) \\
\hline \multicolumn{2}{|c|}{ Total No. of patients } & 3 & 22 & 5 & 30 & 14 & 86 & 25 \\
\hline \multicolumn{2}{|c|}{ Median (days) } & $15-21$ & $15-21$ & $>30$ & $15-21$ & $>30$ & $22-30$ & $>30$ \\
\hline \multicolumn{2}{|c|}{ Mean (days) } & 22 & 15.6 & 35 & 19.4 & 46.1 & - & - \\
\hline
\end{tabular}

dHACM, dehydrated human amnion chorion membrane; STSG, split thickness skin grafting. 
Table 6. Complications of dehydrated human amnion chorion membrane versus split thickness skin grafting

\begin{tabular}{|c|c|c|c|c|}
\hline Study & Burn Depth & $\begin{array}{c}\text { Patients (HTS/ } \\
\text { Contracture) }\end{array}$ & Site & $\%$ \\
\hline \multicolumn{5}{|l|}{ dHACM } \\
\hline & Superficial partial thickness & $3(1)$ & Primary & 33.3 \\
\hline & Deep partial thickness & $22(3)$ & Primary & 13.6 \\
\hline & Full thickness & $5(2)$ & Primary & 40.0 \\
\hline & Total & $30(6)$ & Primary & 20.0 \\
\hline \multicolumn{5}{|l|}{ STSG } \\
\hline Kishikova et $a l^{56}$ & $\begin{array}{r}\text { Superficial partial, deep } \\
\text { partial, full thickness }\end{array}$ & $14(7)$ & Primary & 50.0 \\
\hline Cubison et al..$^{55}$ & $\begin{array}{l}\text { Deep partial/full } \\
\text { thickness }\end{array}$ & $86(49)$ & Primary & 57.0 \\
\hline Lonie et al. ${ }^{54}$ & $\mathrm{~N} / \mathrm{A}$ & $25(21)$ & Primary & 84.0 \\
\hline Grossova et al..$^{53}$ & $\begin{array}{l}\text { Superficial partial, } \\
\text { deep partial }\end{array}$ & $24(5)$ & Primary & 20.8 \\
\hline $\begin{array}{l}\text { Othman Al Shlash } \\
\text { et al. }\end{array}$ & $\mathrm{N} / \mathrm{A}$ & $56(7)$ & Primary & 12.5 \\
\hline Park et al. ${ }^{51}$ & $\mathrm{~N} / \mathrm{A}$ & $210(25)$ & Primary & 11.9 \\
\hline $\begin{array}{l}\text { Chandrasegaram } \\
\text { and Harvey }\end{array}$ & $\mathrm{N} / \mathrm{A}$ & $126(34)$ & Primary & 27.0 \\
\hline Rotatori et al. ${ }^{49}$ & Deep partial/full thickness & $237(152)$ & Donor & 64.1 \\
\hline
\end{tabular}

HTS, hypertrophic scars.

to scarring. We have shown that treatment with dHACM is associated with an accelerated rate of healing compared with STSG with little to no scarring in partial thickness wounds and less scaring in deep and full-thickness burns compared with STSG. The return to normally functioning skin including dynamic compliance, movement, and color is superior in dHACM grafts. The minimal hypertrophic scarring that did occur responded to compression therapy. Pain control was achieved without narcotics in all patients. Infectious complications were absent with the exception of one late localized fungal rash that responded to antifungal ointment. Overall, there was a reduced need for follow-up procedures or clinic visits postop compared with what might be expected from STSG. We will need to continue to follow these children longer term to describe the function and durability of the new tissue dHACM has stimulated.

The ability to regain function especially of sensitive regions such as the hands, face, feet, and genitalia is a major concern in the management of pediatric burns. While autografts ultimately lead to reconstitution of skin overlying these areas, they have also been associated with significant scarring at both primary and donor sites, which limits functional outcomes and many times requires revisional surgeries. ${ }^{5}$ In agreement with other studies, our results provide further support, indicating that the use of dHACM reduces scar tissue formation and enhances wound healing (Figs. 1-3). ${ }^{7,38-40}$ In the setting of complex wounds, chronic inflammation and aberrant immunity are catalysts for scar for- mation. ${ }^{12,16,17}$ Compared with autografts and other allografts, dHACM provides numerous epithelial growth factors and inflammatory mediators that are highly correlated with the physiologic process of changing wound healing environment from chronic inflammation to tissue regeneration. ${ }^{43-47}$ These changes likely account for the mitigation of scar formation after application of dHACM.

Our case series is not without limitations. First, our study was constrained by the lack of a quantitative wound depth measurement. All wounds were sorted into superficial partial, deep partial, and full thickness based on clinical assessment with the depth of burn injury being the primary indication for dHACM graft. Our bias was to treat sites with dHACM that were vulnerable to functional and cosmetic impairment due to scarring.

Second, randomized studies need to be completed to demonstrate the differences in outcomes using split thickness skin graft, other skin substitutes, and dHACM to manage complex burn wounds. Without randomization, it is difficult to demonstrate if there is more rapid healing, fewer complications, and decreased morbidity and mortality by using dHACM. However, the current barrier to widespread use of dHACM is the cost to procure dHACM and poor third-party insurance coverage. Autografts are the accepted standard of care and are available at no additional financial cost to the hospital system; yet do cost significant morbidity to the children treated. We predict that in a decision analysis, the use of dHACM, which eliminates donor-site morbidity and minimizes scar formation, may justify the upfront cost and reduce cost over time by mitigating the subsequent need for reconstructive procedures. Furthermore, the need to transfer patients with small and moderate TBSA deep partial or full-thickness wounds to dedicated burn centers represents both an additional cost and prolonged time to treatment. dHACM can be conveniently stored for rapid application and successful treatment outside of burn centers, ultimately decreasing burn center patient burden and health care costs associated with transfer of care from one system to another.

Collectively, our study suggests that dHACM provides an alternative to the current use of STSG, and is a safe, feasible, and potentially superior substitute for the management of small to moderate TBSA partial and full-thickness pediatric burns.

\section{INNOVATION}

The management of pediatric burns depends on the severity of burn but typically includes 
surgical debridement of nonviable tissue followed by STSG. ${ }^{5,6}$ In the absence of adequate treatment, burns can result in significant scarring, contracture, and loss of function. ${ }^{5}$ We chose dHCAM as a burn graft for patients with injuries to areas vulnerable to functional deficit from scarring such as hands, feet, face, genitalia, and joints. AHACM is associated with an accelerated rate of healing and overall less scarring compared with STSG due to many tissue regenerative factors, such as growth factors and immune modulators.

\section{ACKNOWLEDGMENTS AND FUNDING SOURCES}

This research was supported by the WNY Kiwanis Club.

\section{AUTHOR DISCLOSURE AND GHOSTWRITING}

No competing financial interests exist. The content of this article was expressly written by the authors listed. No ghostwriters were used to write this article.

\section{ABOUT THE AUTHORS}

Natasha Ahuja, MD, is a third-year general surgery resident at University of Buffalo. She is the first author of this article and the corresponding author. Richard Jin, PhD, is a fourth-year medical student at University of Buffalo who has also completed his $\mathrm{PhD}$ in immunology. Colin Powers, MD, is a fifth-year general surgery resident who completed a pediatric surgery research fellowship at University of Buffalo. Alexandria Billi, ANP, is one of the nurse practitioners who assists with the wound care clinic at Oishei's hospital. She has seen all the children from the beginning of the wound care until the end. Kathryn Bass, MD, MBA, is a pediatric surgeon with $>20$ years of experience. She is an associate professor of surgery at the Jacobs School of Medicine at the University of Buffalo and director of the Level 1 Pediatric Trauma Center and codirector of the Pediatric Wound Care Center at Oishei Children's Hospital. She is a fellow of the American College of Surgeons and belongs to many professional organizations, including the American Pediatric Surgical Association, The American Association for the Society of Trauma, and the International Society for Pediatric Wound Care.

\section{REFERENCES}

1. National Hospital Ambulatory Medical Care Survey: Emergency Department Summary Tables. 2015. www.cdc.gov/nchs/data/ahcd/nhamcs emergency/2015_ed_web_tables.pdf (accessed January 4, 2019).

2. American Burn Association (ABA): Burn Injury Fact Sheet. 2018 https://ameriburn.org/wp-content/ uploads/2017/12/nbaw-factsheet 121417-1.pdf (accessed January 15, 2019)

3. ABA: National Burn Repository 2017 Update. 2017. http://ameriburn.org/wp-content/uploads/ 2018/04/2017_aba_nbr_annual_report_summary .pdf (accessed January 15, 2019).

4. ABA: Burn Center Referral Criteria. 2017. http:// ameriburn.org/wp-content/uploads/2017/05/burn centerreferralcriteria.pdf (accessed January 10, 2019).
5. Mathias E, Srinivas Murthy M. Pediatric thermal burns and treatment: a review of progress and future prospects. Medicines (Basel) 2017:4. pii: E91.

6. Romanowski KS, Palmieri TL. Pediatric burn resuscitation: past, present, and future. Burn Trauma 2017:5:26.

7. Glat PM, Davenport T. Current techniques for burn reconstruction using dehydrated human amnion/ chorion membrane allografts as an adjunctive treatment along the reconstructive ladder. Ann Plast Surg 2017;78(Supplement 1):S14-S18.

8. Gause WC, Wynn TA, Allen JE. Type 2 immunity and wound healing: evolutionary refinement of adaptive immunity by helminths. Nat Rev Immunol 2013;13:607-614.

9. Russo MV, Latour LL, McGavern DB. Distinct myeloid cell subsets promote meningeal re- modeling and vascular repair after mild traumatic brain injury. Nat Immunol 2018;19:442-452.

10. Bosurgi L, Manfredi AA, Rovere-Querini P. Macrophages in injured skeletal muscle: a perpetuum mobile causing and limiting fibrosis, prompting or restricting resolution and regeneration. Front Immunol 2011;2:62

11. Wang J, Kubes P. A reservoir of mature cavity macrophages that can rapidly invade visceral organs to affect tissue repair. Cell 2016;165:668678.

12. Novak ML, Koh TJ. Phenotypic transitions of macrophages orchestrate tissue repair. Am J Pathol 2013;183:1352-1363.

13. Arpaia N, Green JA, Moltedo B, et al. A distinct function of regulatory $T$ cells in tissue protection. Cell 2015;162:1078-1089. 
14. Panduro M, Benoist $C$, Mathis D. T reg cells limit IFN- $\gamma$ production to control macrophage accrual and phenotype during skeletal muscle regeneration. Proc Natl Acad Sci U S A 2018;115:E2585-E2593.

15. Molofsky AB, Savage AK, Locksley RM. Interleukin-33 in tissue homeostasis, injury, and inflammation. Immunity 2015;42:1005-1019.

16. Morrison J, Lu QL, Pastoret C, Partridge T, BouGharios G. T-cell-dependent fibrosis in the $\mathrm{mdx}$ dystrophic mouse. Lab Invest 2000;80:881-891.

17. Muñoz-Cánoves P, Serrano AL. Macrophages decide between regeneration and fibrosis in muscle. Trends Endocrinol Metab 2015;26:449-450.

18. Patsalos A, Pap A, Varga T, et al. In situ macrophage phenotypic transition is affected by altered cellular composition prior to acute sterile muscle injury. J Physiol 2017;595:5815-5842.

19. Dal-Secco D, Wang J, Zeng Z, et al. A dynamic spectrum of monocytes arising from the in situ reprogramming of CCR2+ monocytes at a site of sterile injury. J Exp Med 2015;212:447-456.

20. Tidball JG. Regulation of muscle growth and regeneration by the immune system. Nat Rev Immunol 2017;17:165-178.

21. Arnold L, Henry A, Poron F, et al. Inflammatory monocytes recruited after skeletal muscle injury switch into antiinflammatory macrophages to support myogenesis. J Exp Med 2007;204:1057-1069.

22. Kovtun A, Messerer DAC, Scharffetter-Kochanek $\mathrm{K}$, et al. Neutrophils in tissue trauma of the skin, bone, and lung: two sides of the same coin. J Immunol Res 2018;2018:8173983.

23. Minutti CM, Knipper JA, Allen JE, Zaiss DM. Tissuespecific contribution of macrophages to wound healing. Semin Cell Dev Biol 2017;61:3-11.

24. Cruz MS, Diamond A, Russell A, Jameson JM. Human $\alpha \beta$ and $\gamma \delta$ T cells in skin immunity and disease. Front Immunol 2018:9:1304.

25. Rigamonti E, Zordan P, Sciorati C, et al. Macrophage plasticity in skeletal muscle repair. Biomed Res Int 2014;2014:560629.

26. Heredia JE, Mukundan L, Chen FM, et al. Type 2 innate signals stimulate fibro/adipogenic progenitors to facilitate muscle regeneration. Cell 2013; 153:376-388.

27. Ten Broek RW, Grefte S, Von den Hoff JW. Regulatory factors and cell populations involved in skeletal muscle regeneration. J Cell Physiol 2010; 224:7-16.

28. Ceafalan LC, Popescu BO, Hinescu ME. Cellular players in skeletal muscle regeneration. Biomed Res Int 2014;2014:957014.

29. Almada AE, Wagers AJ. Molecular circuitry of stem cell fate in skeletal muscle regeneration, ageing and disease. Nat Rev Mol Cell Biol 2016; 17:267-279.

30. Shireman PK, Contreras-Shannon V, Ochoa O, et al. MCP-1 deficiency causes altered inflammation with impaired skeletal muscle regeneration. J Leukoc Biol 2007;81:775-785.
31. Wang H, Melton DW, Porter L, et al. Altered macrophage phenotype transition impairs skeletal muscle regeneration. Am J Pathol 2014;184:1167-1184.

32. Burzyn D, Kuswanto W, Kolodin D, et al. A special population of regulatory $T$ cells potentiates muscle repair. Cell 2013;155:1282-1295.

33. Ali N, Rosenblum MD. Regulatory T cells in skin. Immunology 2017;152:372-381.

34. Tonkin J, Temmerman L, Sampson RD, et al. Monocyte/macrophage-derived IGF-1 orchestrates murine skeletal muscle regeneration and modulates autocrine polarization. Mol Ther 2015;23:1189-1200.

35. Varga T, Mounier R, Patsalos A, et al. Macrophage PPAR $\gamma$, a lipid activated transcription factor controls the growth factor GDF3 and skeletal muscle regeneration. Immunity 2016;45:1038-1051.

36. Varga T, Mounier R, Horvath A, et al. Highly dynamic transcriptional signature of distinct macrophage subsets during sterile inflammation, resolution, and tissue repair. J Immunol 2016;196:4771-4782.

37. Deng B, Wehling-Henricks M, Villalta SA, et al. IL10 triggers changes in macrophage phenotype that promote muscle growth and regeneration. J Immunol 2012;189:3669-3680.

38. Reilly DA, Hickey S, Glat P, et al. Clinical experience: using dehydrated human amnion/chorion membrane allografts for acute and reconstructive burn care. Ann Plast Surg 2017;78:S19-S26.

39. Serena TE, Carter MJ, Le LT, et al. A multicenter, randomized, controlled clinical trial evaluating the use of dehydrated human amnion/chorion membrane allografts and multilayer compression therapy vs. multilayer compression therapy alone in the treatment of venous leg ulcers. Wound Repair Regen 2014;22:688-693.

40. Zelen CM, Serena TE, Denoziere G, Fetterolf DE. A prospective randomised comparative parallel study of amniotic membrane wound graft in the management of diabetic foot ulcers. Int Wound $\mathrm{J}$ 2013;10:502-507.

41. Bourne G. The foetal membranes. A review of the anatomy of normal amnion and chorion and some aspects of their function. Postgrad Med J 1962; 38:193-201.

42. Niknejad H, Peirovi $H$, Jorjani $M$, et al. Properties of the amniotic membrane for potential use in tissue engineering. Eur Cells Mater 2008; 15:88-99.

43. Koob TJ, Rennert R, Zabek N, et al. Biological properties of dehydrated human amnion/chorion composite graft: implications for chronic wound healing. Int Wound J 2013;10:493-500.

44. Koob TJ, Lim JJ, Massee M, et al. Properties of dehydrated human amnion/chorion composite grafts: implications for wound repair and soft tissue regeneration. J Biomed Mater Res Part B Appl Biomater 2014;102:1353-1362.

45. Massee M, Chinn K, Lei J, et al. Dehydrated human amnion/chorion membrane regulates stem cell activity in vitro. J Biomed Mater Res B Appl Biomater 2016;104:1495-1503.
46. Maan ZN, Rennert RC, Koob TJ, et al. Cell recruitment by amnion chorion grafts promotes neovascularization. J Surg Res 2015;193:953-962.

47. Lei J, Priddy LB, Lim JJ, et al. Identification of extracellular matrix components and biological factors in micronized dehydrated human amnion/chorion membrane. Adv Wound Care 2017;6:43-53.

48. Soleimani T, Evants TA, Sood R. Predictors of reconstructive surgery among burn patients. Plast Recont Surg 2015;136(4 Suppl):126.

49. Rotatori RM, Starr B, Peak M, et al. Prevalence and risk factors for hypertrophic scarring of split thickness autograft donor sites in a pediatric burn population. Burns 2019;45:1066-1074.

50. Othman Al Shlash S, Omran Al Mandani J, Ismail El Deib J, et al. Demographic characteristics and outcomes of burn patients requiring skin grafts: a tertiary hospital experience. Int J Burns Trauma 2016;6:30-36.

51. Park YS, Lee JW, Huh GY, et al. Algorithm for primary full-thickness skin grafting in pediatric hand burns. Arch Plast Surg 2012;39:483-488.

52. Chandrasegaram MD and Harvey J. Full thickness vs. split-skin grafting in pediatric hand burns - a 10-year review of 174 cases. J Burn Care Res 2009;30:867871.

53. Grossova I, Zajjcek R, Kubok R, Smula MC. The treatment of palmar contact burns in children: a fiveyear review. Ann Burns Fire Disasters 2017;30:5-8.

54. Lonie S, Baker P, Teixeira RP. Healing time and incidence of hypertrophic scarring in paediatric scalds. Burns 2017:43:509-513.

55. Cubison TCS, Pape SA, Parkhous N. Evidence for the link between healing time and development of hypertrophic scars (HTS) in paediatric burns due to scald injury. Burns 2006;32:992-999.

56. Kishikova L, Smith MD, Cubison TCS. Evidence based management for paediatric burn: new approaches and improved scar outcomes. Burns 2014;40:1530-1537.

57. Branski LK, Herndon DN, Pereira C, et al. Longitudinal assessment of Integra in primary burn management: a randomized pediatric clinical trial. Crit Care Med 2007;35:2615-2623.

58. Transplant and Tissue Engineering. East Hanover, NJ, USA: Novartis, 2002. www.pharma.us .novartis.com/sites/www. pharma.us.novartis.com/ files/n_int_050273.pdf (accessed April 15, 2019).

\footnotetext{
Abbreviations and Acronyms

$\mathrm{dHACM}=$ dehydrated human amnion chorion membrane

HTS $=$ hypertrophic scarring

$\mathrm{LE}=$ lower extremity

$\mathrm{LLE}=$ left lower extremity

LUE $=$ left upper extremity

$\mathrm{OR}=$ operating room

$\mathrm{PIP}=$ proximal interphalangeal

RUE $=$ right upper extremity

STSG $=$ split thickness skin graft

TBSA $=$ total body surface area

VSS $=$ Vancouver Scar Scale
} 